Foro Interno. Anuario de Teoría Política

ISSN: 1578-4576

http://dx.doi.org/10.5209/FOIN.57207

\title{
Violencia y Estado. Una propuesta de clasificación para la teoría de la guerra justa
}

Miguel Paradela López ${ }^{1}$

Recibido: 26 de agosto de 2016 / Aceptado: 14 de julio de 2017

Resumen. El presente artículo busca aportar un criterio de categorización que permita plantear una diferenciación en función de la legitimación al recurso a la guerra como medio de resolución de conflictos entre Estados, para así poder distinguir los principales enfoques de la teoría de la guerra justa. De esta manera se diferencian en primer lugar el pacifismo, que rechaza cualquier tipo de respuesta violenta por parte de un Estado; la autodefensa, que limita esa actuación a la defensa frente a una agresión previa; el intervencionismo, que defiende las acciones militares en supuestos de violaciones de derechos humanos; y el belicismo, que rechaza cualquier limitación a la capacidad bélica de los Estados. El artículo concluye mostrando cómo esta propuesta de clasificación aporta una aproximación sencilla con el potencial de resumir las posturas de los distintos autores, así como de mostrar los posicionamientos de estos sobre conflictos actuales.

Palabras clave: Guerra justa; categorización; violencia; Estado.

\section{[en] Violence and the State. A Classification Proposal for Just War Theory}

\begin{abstract}
This article develops a categorization criterion that allows differentiation according to the legitimation of recurring to war as a means of solving conflicts among states, and identifies the main foci of just war theory. In this sense, it distinguishes pacifism, that rejects any kind of violent response by a state; from self-defense, that limits this action to defense against a prior aggression; interventionism, that legitimates military actions in contexts of human rights violations; and warmongering, that denies any kind of limitation in the military reach of states. This article concludes by showing how this proposal provides a parsimonious perspective with the added possibility of summarizing and exhibiting the positions of several scholars on current conflicts.
\end{abstract}

Keywords: Just war; categorization; violence; state.

Cómo citar: Miguel Paradela López, "Violencia y Estado. Una propuesta de clasificación para la teoría de la guerra justa”: Foro Interno. Anuario de Teoría Política, vol. 17 (2017), pp. 97-120.

\section{Introducción}

El momento actual muestra un escenario internacional marcadamente violento, en el que proliferan los conflictos bélicos entre Estados, los atentados terroristas e incluso las intervenciones militares. Del mismo modo, vuelven a tener lugar intensos deba-

1 Grupo de Investigación “Observatorio Público”. Tecnológico de Antioquía-Institución Universitaria (Colombia) E-mail: miguel.paradela@tdea.edu.co 
tes sobre la legitimidad de determinadas actuaciones bélicas, en las que a menudo se contraponen intereses geoestratégicos frente a cuestiones morales. No obstante, estos discursos han tendido a ignorar la muy extensa producción académica que lleva siglos trabajando este tipo de discusiones. En este hecho ha influido, sin duda, una cierta desconexión de las teorías morales sobre los conflictos bélicos — la denominada teoría de la guerra justa - con la práctica de las actuaciones militares contemporáneas.

En este sentido, para la ciencia política siempre ha sido necesario acudir a criterios de categorización como vía hacia el avance en el estudio académico, como sucede con el índice de democratización de los Estados, la distinción de Juan José Linz (1926-2013) sobre tipos de autoritarismo, la categorización del capital social por parte de Robert Putnam, la poliarquía de Robert Dahl (1915-2014), los modelos de democracia de David Held, las democracias mayoritarias y consensuadas de Arend Lijphart o, centrados en los conflictos bélicos, la diferenciación de Michael Doyle en realismo, liberalismo y socialismo.

Siguiendo con esta serie de esfuerzos, el propósito de este artículo es aportar criterios para la categorización de las diversas posiciones que pueden adoptarse ante la legitimación del recurso a la guerra como medio de resolución de conflictos entre Estados, realizando un acercamiento a los principales enfoques sobre esta misma cuestión desde la teoría de la guerra justa. Se diferencia en primer lugar el pacifismo, que rechaza cualquier tipo de respuesta violenta por parte de un Estado; la autodefensa, que limita esa actuación a la defensa frente a una agresión previa; el intervencionismo, que defiende las intervenciones militares en supuestos de violaciones de derechos humanos; y el belicismo, que rechaza limitaciones a la capacidad bélica de los Estados. Para clarificar dicha distinción, en cada una de estas cuatro posturas se busca dar respuesta a las siguientes cuestiones básicas: cómo se conciben las relaciones internacionales; qué papel desempeña la guerra en dichas relaciones; y por qué métodos de resolución de controversias se inclinan.

Además, el desarrollo de esta clasificación permite una doble interacción entre las diversas corrientes: la tensión dentro de los diferentes grupos —véase la interacción entre pacifismo emotivo y pacifismo racional con respecto a la importancia de la filosofía - o directamente entre las corrientes entre sí — por ejemplo, la crítica al pacifismo por su "utopismo"-. Así, aunque el artículo se desarrolla por categorías, no pierde su propósito dialéctico y discursivo, mostrando la interacción de los distintos autores y corrientes. En definitiva, el artículo busca aportar una aproximación sencilla con el potencial de resumir las posturas de distintos autores reconocidos internacionalmente, mostrando sus respectivos posicionamientos sobre los conflictos actuales.

\section{La Teoría de la Guerra Justa y la disposición al uso de la violencia}

Aunque la guerra como hecho moral ha sido objeto de frecuente estudio a lo largo de la historia, la mayoría de estos acercamientos se han centrado en la naturaleza del hombre con respecto al conflicto y a la lucha —y a través de esa cuestión, en su papel dentro de las relaciones entre Estados - o en la descripción de las diferentes corrientes históricas, analizando las particularidades de cada una de ellas. A pesar de que esta tarea ha permitido una importante categorización de los autores más representativos de la teoría de la guerra justa, no ha logrado realizar una aproximación práctica hacia la disposición al uso de la violencia en conflictos concretos contemporáneos. En este sentido, desde el presente artículo se propone la siguiente clasificación. 


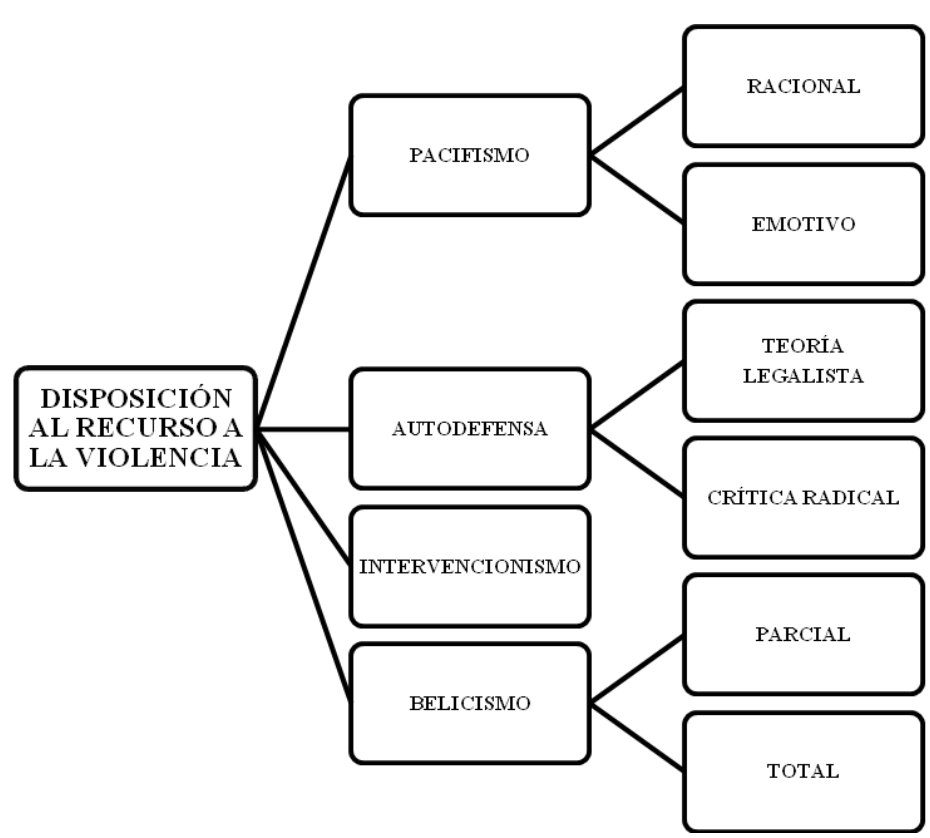

Figura 1. Enfoques sobre la disposición al recurso a la violencia.

\section{Pacifismo}

En este primer grupo se engloban todas aquellas posturas que defienden la renuncia absoluta a la guerra en las relaciones internacionales, abogando en su lugar por la resolución de conflictos a través de métodos no violentos. Incluso en los supuestos en los que exista una invasión o agresión militar de un Estado sobre otro, los autores del pacifismo se posicionan a favor de medidas de presión internacional o resistencia pasiva civil que hagan insostenible el mantenimiento de la ocupación y consigan que el pueblo pueda recuperar su soberanía. Así, desde el pacifismo se sostiene que existen métodos de presión de índole económica y política que obligan al Estado agresor a que cese en su agresión y a que se comprometa con el respeto de los derechos humanos y la paz internacional. Con respecto a estos mecanismos pacíficos de resolución de controversias, tales autores rechazan el recurso a la violencia, ya sea por factores puramente filosóficos — por el daño moral que supone iniciar tales conflictos - o influido por elementos pragmáticos — por considerar que la violencia nunca va a ser la solución más eficiente ni más estable a un conflicto internacional-.

Sin embargo, es necesario aclarar previamente que esta postura no rechaza necesariamente cualquier tipo de violencia estatal. Por ejemplo, no asumen las bases filosóficas del pensamiento anarquista, que consideran el Estado como un elemento de opresión de parte de la población sobre la otra. Por el contrario, el Estado para estos autores constituye a menudo el elemento garante de la seguridad entre los pueblos y comunidades, la autoridad última que evita que los conflictos entre los individuos se resuelvan por vías violentas. En este sentido, el pacifismo reconoce la importancia de 
la labor estatal de vigilancia y protección de la población nacional, rechazando únicamente la actuación violenta hacia o contra el exterior. Ubicado dentro de la clasificación propuesta por Michael Mann², estos autores rechazan la militarización como fuente de movilización social, no la actividad policial de protección de la población ${ }^{3}$.

Por tanto, si bien es legítimo que un Estado ejerza cierta violencia para mantener la seguridad entre la población - justificándolo filosóficamente como un mal necesario-, estos autores en ningún caso justifican la violencia hacia el exterior: tanto en la invasión a un Estado extranjero como en la resistencia militar contra fuerzas invasoras. Sin duda, es ciertamente polémica esta dicotomía, especialmente por las dificultades para justificar la diferenciación entre la protección policial de la población - que sería una actuación legítima - y la resistencia ante un ejército invasor —que sería ilegítima - En definitiva, el Estado pacifista, tal y como aquí se entiende, es aquel que únicamente recurre a la violencia para mantener el respeto de las normas, pero renuncia a ella para cualquier otro uso que exceda tal tarea. Y por ello mismo, cuando se hable de la violencia en este apartado se referirá a la violencia del Estado hacia elementos externos: atacando a un tercer Estado o defendiéndose de él.

Aunque esta posición es relativamente joven y no cuenta con una escuela extensa, en comparación con las corrientes de la autodefensa y del intervencionismo ${ }^{4}$, existe una serie de autores con un pensamiento completo y prolijo. En este sentido, destacan las obras de Gene Sharp - The Politics of Nonviolent Action ${ }^{5}$ o Waging Nonviolent Struggle: 20th Century Practice and 21st Century Potential ${ }^{6}$ - en las que desarrolla diversas posturas en defensa de la resistencia pacífica. También son reseñables las obras de Mulford Sibley ${ }^{7}$ o Robert Holmes ${ }^{8}$, aunque merece una mención especial iIndignaos!, de Stéphane Hessel, inspirador intelectual de las protestas juveniles del año 2011, donde afirma su convencimiento sobre la no violencia y la conciliación entre culturas9.

Con respecto a las características del pacifismo, a pesar de que los diferentes autores muestran numerosas particularidades, pueden observarse tres características comunes a todos ellos: la creencia en la cooperación internacional como mecanismo para evitar los conflictos entre Estados, el rechazo a la violencia como forma de resolver dichos conflictos y la defensa de los mecanismos de resistencia pacífica como la herramienta más efectiva contra las agresiones violentas.

2 Michael Mann, Las fuentes del poder social, trad. de Fernando Santos Fontenla, Alianza Editorial, Madrid, 1991, pp. 114ss.

3 Sería interesante plantear el grado de represión que los autores pacifistas podrían tolerar, incluso en regímenes democráticos. Sin embargo, el estudio de tal cuestión excede las limitaciones de este artículo, quedando emplazado como futura línea de investigación.

4 Esta afirmación debe precisarse, puesto que sí pueden encontrarse movimientos pacifistas en la historia antigua, como lo fueron los numerosos casos dentro del cristianismo primitivo que se opusieron a la participación en el ejército romano. O del mismo modo, su resistencia pacífica frente a la represión imperial por la no aceptación el politeísmo romano. No obstante, sí puede afirmarse que no existe una corriente pacifista antigua claramente distinguible, al margen de escritores en momentos puntuales.

5 Gene Sharp, The Politics of Nonviolent Action, Porter Sargent, Boston, 1973, passim.

6 Gene Sharp y Joshua Paulson, Waging Nonviolent Struggle: 20th Century Practice and 21st Century Potential, Extending Horizons Books, Boston, 2005, passim.

$7 \quad$ Mulford Sibley (ed.), The Quiet Battle: Writings on the Theory and Practice of Non-violent Resistance, Beacon Press, Boston, 1963, passim.

8 Robert L. Holmes, On War and Morality, Princeton University Press, Princeton, 2014, passim.

9 Stéphane Hessel, ;Indignaos!, trad. de María Belvis Martínez García, Destino, Barcelona, 2011, p. 41. 
Con respecto a la primera cuestión, estos autores entienden que la cooperación internacional puede resolver los conflictos entre Estados, generando contextos de diálogo y cooperación internacional que aparten la violencia de las relaciones internacionales. De hecho, consideran que, en cierta medida, esta solución es viable para alcanzar estabilidad internacional en el largo plazo, ya que los conflictos militares generan dinámicas de vencedores y vencidos que dificultan una posible reconciliación.

En segundo lugar, los autores de esta postura entienden que la solución violenta, sea cual sea la situación que la provocó, tiende a conducir a unos costes imprevisibles, pero habitualmente superiores, a los objetivos que se trataban de proteger ${ }^{10}$. Por tanto, aunque la resistencia o el ataque militar puedan parecer justificados moralmente, tales actuaciones terminarán probablemente desencadenando unos costes mucho mayores de los previstos - costes que podrían evitarse con métodos de resistencia no violentos-.

Por último, en supuestos de agresión a los Estados o a las comunidades, estas posturas abogan por acudir a mecanismos de resistencia pacífica, ya sea a través de ellos mismos o mediante la presión internacional, que hagan imposible el mantenimiento de la actuación o de la agresión inmoral. Tomando en consideración que la defensa o la agresión armada no son opciones éticamente aceptables, el pacifismo propone una serie de medidas basadas en la colaboración internacional y en la resistencia no violenta de la población. A lo largo de la historia se han visto ejemplos de movilizaciones pacíficas con profundo impacto en las autoridades agresoras u ocupantes: desde el movimiento independentista indio a la lucha contra la segregación racial en Estados Unidos o incluso, dentro de sus diferentes etapas, en la lucha feminista. El pacifismo, tal y como se entiende en esta categoría, supone:

Una apuesta por formas de cooperación, compromiso y negociación. Las cuales implican una visión de mayor confianza en el género humano; una concepción del conflicto más abierta, participativa y alternativa; la capacidad de compromiso renovado con la justicia; y la construcción de unas relaciones fundamentadas en la cultura de la paz ${ }^{11}$.

Cabe destacar en este aspecto la distinción entre la paz negativa — como la ausencia de conflictos militares-y la paz positiva - "la interacción entre individuos y grupos, de modo tal que sea el factor estructurante de una sociedad desjerarquizada e igualitaria" 12 .

Por otro lado, en referencia a la tipología del pacifismo se propone la distinción en dos corrientes en virtud de los motivos por los que rechazan el recurso a la violencia: pacifismo racional - que rechaza la violencia por los costes que genera-y pacifismo emotivo — por la inmoralidad del ejercicio de la violencia en sí misma-.

10 Como se estudia posteriormente, estos costes pueden entenderse desde una perspectiva material —en el caso del pacifismo racional - como inmaterial — en el caso del pacifismo emotivo- . Por ejemplo, para Gandhi el daño en el espíritu indio de conseguir la independencia de manera violenta habría sido inconmensurable.

11 Mario López Martínez, "La sociedad civil por la paz", en Historia de la paz: tiempos espacios y actores, Universidad de Granada, Granada, 2000, pp. 328-329.

12 María Luisa Femenías, "Pacifismo, feminismo y utopía": Daimon. Revista Internacional de Filosofia, n. 4 (2011), p. 51. 
Con respecto a la primera categoría, engloba a aquellos autores que fundamentan su rechazo a cualquier tipo de guerra en los costes que dicho conflicto violento puede generar al conjunto de la población. Según este pensamiento, el precio de cualquier guerra - en muertes, propiedades destruidas, migraciones forzadas...- siempre es, o al menos tiene potencialidad de ser, superior al objetivo que busca alcanzar ${ }^{13}$. Por tanto, incluso aunque una guerra busque objetivos limitados en favor de una causa justa, la tendencia a la brutalidad de los conflictos puede llevar a que el coste sea mucho mayor que el esperado y, probablemente, al que habría supuesto la inacción ${ }^{14}$.

Así, desde esta postura, la guerra se rechaza porque no sirve para solucionar problemas concretos, sino más bien para agravarlos: la guerra, además de ser un método inmoral, es ineficaz para solucionar los problemas entre los Estados. En este sentido, la obra de Peter Ackerman y Chris Kruegler ${ }^{15}$ muestra la potencialidad de las políticas de resistencia contra autoridades que emplean la represión violenta contra la población. Del mismo modo, Robert L. Holmes ${ }^{16}$ plantea la necesidad de renunciar a la violencia entre Estados por los riesgos tan elevados - militares en general y nucleares en particular - que se asumirían de continuar con las tendencias belicistas.

Continuando con Gene Sharp, este autor propone un sistema que denomina political jiu-jitsu, una movilización social que sostenga actuaciones no violentas con el objetivo de que cualquier actuación en su contra perjudique más a quien la llevó a cabo, puesto que la disparidad de fuerzas — violentas contra pacíficas_-, así como la clara voluntad no violenta, deslegitima a quien lleva a cabo el ataque a la vez que genera simpatías hacia los agredidos ${ }^{17}$. Por ejemplo, Jonathan Glover describe la potencialidad de ese tipo de lucha, mostrando numerosos ejemplos de cómo la acción no violenta genera contradicciones en los sujetos que la tienen que reprimir ${ }^{18}$.

Por otro lado, existe una segunda categoría, que no se apoya ya en la ineficacia de la guerra, sino que arraiga más fuertemente en argumentos filosóficos-morales. El denominado pacifismo emotivo considera moralmente inasumible el recurso a la guerra en tanto que priva de derechos esenciales - a la vida y a la libertad - a sus nacionales o a los de otras poblaciones. Partiendo de posturas de reconocimiento de derechos humanos esenciales, sería inmoral privar de los mismos a otras personas, aunque estos los estén negando a otros. Incluso aunque sea para mantener la propia integridad, tales comportamientos no pueden estar nunca legitimados, sino que debe acudirse a acciones de índole pacífica que logren los mismos objetivos.

En este segundo grupo podría ubicarse a Mahatma Gandhi (1869-1948) y su teoría de la no violencia, en la que la resistencia armada contra las autoridades inglesas era rechazada a favor de la movilización civil, incluso aunque la gran motivación y la enorme diferencia en cuanto a superioridad numérica sugiriese una fácil victoria militar india. El profundo rechazo de este autor a la violencia le llevó a descartarla a favor de la movilización y resistencia no violenta para estrangular al gobierno bri-

13 No puede dejar de observarse aquí la similitud con los planteamientos de Carl von Clausewitz (1780-1831), quien hablaba de la importancia de las tendencias en conflicto en lo que él denominaba la guerra total: como, pese a que un conflicto comience con aspiraciones limitadas, los esfuerzos en alcanzar la victoria llevarán a un incremento cuantitativo y cualitativo de la violencia.

14 Gene Sharp, Exploring Nonviolent Alternatives, Porter Sargent, Boston, 1970, pp. 50ss.

15 Peter Ackerman y Chris Kruegler, Strategic Nonviolent Conflict: The Dynamics of People Power in the Twentieth Century, Praeger, Westport, 1994, passim.

16 Holmes, On War and Morality, pp. 260-298.

17 Sharp, The Politics of Nonviolent Action, p. 110.

18 Jonathan Glover, Humanity: A Moral History of Twentieth Century, Nota Bene, New Haven, 2013, pp. 47ss. 
tánico y obligarle a negociar la independencia india. En este sentido el rechazo a la violencia es mayor si cabe que el anterior, puesto que cometer actos contra la vida de otras personas no puede estar justificado ni ante la peor de las situaciones posibles.

Lo mismo podría decirse del pensamiento de Martin Luther King Jr. (19291968), quien no solo fomentó un fuerte movimiento pacífico contra la segregación racial en Estados Unidos ${ }^{19}$, sino que también lideró una intensa campaña contra el militarismo estadounidense y, más concretamente, contra la Guerra de Vietnam ${ }^{20}$. Cabe destacar cómo, incluso en el contexto de represión por parte de las autoridades estadounidenses y los numerosos asesinatos por parte de organizaciones supremacistas - especialmente del Ku Klux Klan-, mantuvo el rechazo a la resistencia armada, abogando en su lugar por la protesta pacífica. Incluso podría argumentarse que el pensamiento tardío ${ }^{21}$ de Nelson Mandela (1918-2013) comparte estos valores, puesto que trató de reconciliar a la población sudafricana y evitar que la salida del apartheid generase una guerra racial. Del mismo modo, la Sociedad Religiosa de los Amigos - más conocida como cuáqueros - o el movimiento Amish, también rechazan categóricamente la violencia como método de resolución de conflictos, en este caso tanto en el ámbito interno como en el externo ${ }^{22}$.

Por último, una parte sustancial del movimiento feminista ha tomado la resistencia no violenta como el elemento esencial a través del cual alcanzar el empoderamiento de la mujer y la equiparación en derechos con los hombres. Además, dentro de esta lucha el pacifismo toma un carácter esencial, en tanto consideran las actitudes militaristas como el resultado de la exaltación de los valores culturalmente asociados a la masculinidad agresividad, conflicto...-. Destacan en este sentido autoras tan relevantes como Simone de Beauvoir (1908-1986) ${ }^{23}$, Petra Kelly (1947-1992) ${ }^{24}$ o Carole Pateman ${ }^{25}$.

Por otro lado, parece traslucirse en ambas corrientes la creencia de que la tendencia a la violencia entre Estados genera una serie de inercias hacia la perpetuación de ese tipo de relaciones: si bien, en el pacifismo emotivo podemos observar un rechazo categórico a la violencia, por suponer actos inmorales que necesariamente dejan una huella imborrable en el ser humano, el pacifismo racional parece fundamentarse más en la acción y reacción de los Estados entre sí, tanto en el corto plazo - con respecto a la movilización de fuerzas durante el transcurso del conflicto-, como en el largo plazo - generando dinámicas belicistas en las sociedades que den lugar a nuevas luchas-.

A modo de comentario general, es innegable que la corriente pacifista hunde fuertemente sus raíces en la filosofía, posiblemente mucho más que cualquiera de las corrientes que se exponen en las páginas siguientes. Más concretamente, la distinción entre pacifismo racional y pacifismo emotivo refleja en cierta medida la ya estudiada distinción entre resistencia no violenta y política de la no violencia ${ }^{26}$. Si

19 Martin Luther King, Jr., Strength to Love (1963), Editorial Collins, London, 1977, passim.

20 Martin Luther King, Jr., "Beyond Vietnam", en A Call to Conscience: The Landmark Speeches of Martin Luther King, Jr., ed. de Clayborne Carson, IPM/Warner Books, New York, 2001.

21 Parece claro que en su juventud su pensamiento era más radical, participando en Umkhonto we Sizwe, que llevó a cabo actividades violentas contra el gobierno sudafricano.

22 Peter Brock, The Quaker Peace Testimony 1660 to 1914, Sessions Book Trust, New York, 1990, passim.

23 Simone de Beauvoir, El segundo sexo (1949), trad. de Pablo Palant, Editorial Siglo Veinte, Buenos Aires, 1969, passim.

24 Petra Kelly, Fighting for Hope, Chatto \& Windus, London, 1984, passim.

25 Carole Pateman, The Sexual Contract, Stanford University Press, Stanford, 1988, passim.

26 Kathleen Gallaguer Cunningham, "Understanding Strategic Choice: The Determinants of Civil War and Nonviolent Campaign in Self-determination Disputes": Journal of Peace Research, vol. 50, n. 3 (2013), pp. 291-304. 
bien podría ser incorrecto argumentar que alguno de los dos pacifismos no obedece a un compromiso filosófico con la paz y la no violencia, sí puede defenderse que no lo hacen desde el mismo punto de partida ni con la misma intensidad. Mientras que los autores más cercanos al pacifismo emotivo fundamentan su posición en profundas convicciones contra la violencia, en el pacifismo racional también cobran importancia otra serie de factores más pragmáticos — como los costes de la lucha violenta, los peligros de la movilización civil, etc.-

Por último, si bien los planteamientos pacifistas han generado grandes apoyos entre amplios sectores de la población, igual de intensas han sido las críticas recibidas por su "utopismo": ya sea por facilitar indirectamente el ascenso de los movimientos violentos $^{27}$, por generar la deshumanización del enemigo ${ }^{28}$ o por desmovilizar a la población civil para que no se rebele contra el gobierno ${ }^{29}$. Para ilustrar esta interacción, posteriormente se expone la crítica de Michael Walzer, autor conocido por su defensa del intervencionismo, a los planteamientos pacifistas.

\section{Autodefensa}

A diferencia de la corriente pacifista, con un origen relativamente moderno, la autodefensa puede encontrarse mucho antes: frente al belicismo de los Estados europeos de la Edad Media y de la Edad Moderna surgió una generación de pensadores que fueron incorporando - la mayoría desde una perspectiva liberal - la necesidad de limitar la resolución violenta de las controversias entre los Estados.

En este sentido, la autodefensa comparte una parte importante de las bases argumentativas del pacifismo y defiende, también, que la relación natural entre los Estados es la colaboración y cooperación pacífica porque generan un mayor beneficio económico, político y cultural que el conflicto militar. Así, considera que la época pasada de conflictos continuos entre Estados debe ser superada por la filosofía liberal, sustituyendo las guerras por mecanismos pacíficos de resolución de conflictos. Por todo ello, la violencia debe quedar descartada de los mecanismos de resolución de controversias entre Estados, puesto que implica un gran sufrimiento para las poblaciones litigantes a la vez que niega la soberanía política de los Estados. Según estos autores, las guerras, incluso cuando terminan, dan lugar a resentimientos que sientan las bases de la siguiente guerra. Por tanto, y en palabras de Inmanuel Kant (1724-1804), "el conflicto es necesario en la vida personal y estatal, no así el recurso a la violencia" 30 .

No obstante, la autodefensa diverge del pacifismo al afirmar que cuando un Estado se ve atacado por otro y está en riesgo la libertad o incluso la supervivencia de su comunidad, la resistencia por la vía armada está moralmente legitimada. Dado que el Estado es la forma en la que se estructuran las sociedades modernas cons-

27 Henry Kamen, “Las paradojas del pacifismo". Disponible en: http://personales.upv.es/ jvoltra/textos/textostem/ pacifismo.htm (23-6-2017).

28 Carl Schmitt, El nomos de la tierra en el Derecho de Gentes del “Ius publicum europaeum” (1950), trad. de Dora Schilling Thon, Centro de Estudios Políticos y Constitucionales, Madrid, 1979, passim.

29 Leon Trotsky, "Pacifism as the Servant of Imperialism": Communist International, New Series, n. ${ }^{\circ} 5$ (1917), passim. Disponible en: https://www.marxists.org/archive/trotsky/1917/xx/pacifism.htm (23-6-2017).

30 Immanuel Kant, Idea para una historia universal en sentido cosmopolita (1784), trad. de Concha Roldán Panadero y Roberto Rodríguez Aramayo, Tecnos, Madrid, 1994, p. 8. 
tituye el garante del modelo de vida de la comunidad: su cultura, su lenguaje, sus tradiciones... ${ }^{31}$ Por tanto, cuando el Estado está en peligro - y por ende el conjunto de la comunidad - resulta legítimo recurrir a la violencia para repeler la agresión. La defensa frente a un ataque constituye el mal menor: lanzarse al combate para no doblegarse ante una autoridad extranjera. Desde este punto de vista, los perjuicios de la guerra son tan elevados que solo está moralmente justificado combatir cuando está en peligro la supervivencia misma del Estado. Ante una invasión armada que amenaza con una conquista del país el recurso ante organismos internacionales o tribunales de mediación carece de sentido, ya que la pérdida de la soberanía del Estado podría haberse consumado para cuando estos mecanismos puedan haber tomado una decisión.

Por tanto, esta postura entiende la teoría de la guerra justa indisolublemente unida a la defensa: solo puede actuarse de manera violenta cuando se ponga en riesgo la existencia misma de la comunidad. Así, rechazan la legitimación de actuaciones militares contra Estados que no han emprendido acciones militares previas contra el Estado. Tales actuaciones no solo son una violación de la soberanía estatal —pues impiden la resolución real del conflicto- sino que además ponen en riesgo la estabilidad de la Comunidad Internacional — que puede verse inmersa en un conflicto militar global - . La respuesta del intervencionismo en este punto es particular, ya que sostiene que la intervención militar es el garante último de la estabilidad internacional, puesto que impide la comisión de crímenes de tal gravedad que, si no son atajados de raíz, pueden extenderse a otros países. Por ejemplo, tolerar la comisión de crímenes de genocidio porque se circunscriben a las fronteras de un Estado puede implicar su generalización, en tanto los Estados perciban que no hay un castigo a tal tipo de crimen ${ }^{32}$.

Por otro lado, dentro de los autores englobados dentro de la autodefensa pueden exponerse una serie de caracteres comunes a todos ellos, como son la fe en la cooperación internacional, la concepción claramente negativa de la guerra y la legitimación de esta únicamente como respuesta a agresiones que ponen en riesgo la existencia de la comunidad y de los miembros que la conforman. Con respecto a las dos primeras, al coincidir con los planteamientos del pacifismo ya desarrollados, quedan remitidos a ese apartado.

Resulta interesante, sin embargo, cómo estos autores, a pesar de abogar por una resolución pacífica de las controversias, no renuncian totalmente al uso de la violencia. Entienden que todo Estado tiene derecho a defenderse frente a un ataque extranjero, puesto que lo que está en juego es la supervivencia o autonomía de esa comunidad. Por tanto, la violencia es legítima cuando tiene lugar como respuesta a una agresión previa que ha puesto en riesgo al Estado o a los miembros que la conforman, incluso aunque reconozcan la inmoralidad de esta acción. De hecho, desde un punto de vista filosófico, el pacifismo puede verse estructuralmente unido a la autodefensa; en cierto sentido es el siguiente paso en el pragmatismo que ya se observó en el pacifismo. Si frente al pacifismo emotivo ya existía este proceso representado por el pacifismo racional — que no solo incluía la inmoralidad del conflicto, sino

31 Véase al respecto la teoría de la narración histórica expuesta en Alasdair Macintyre, Tras la virtud, trad. de Amelia Valcárcel, Crítica, Barcelona, 1988, pp. 320-322.

32 Michael Walzer, Just and Unjust Wars: A Moral Argument with Historical Illustrations, Basic Books, New York, 2006, pp. 107-108. 
también otros elementos materiales - este se agudiza en la autodefensa: aunque el escenario ideal es la no violencia y la resolución pacífica de las controversias, la realidad de un ataque que pone en peligro la existencia misma de la comunidad obliga a recurrir a la resistencia armada.

Con respecto a la distinción de las tipologías de la autodefensa pueden distinguirse la teoría legalista y la teoría de la crítica radical, en función de la consideración sobre la efectividad del derecho internacional como solución de los conflictos internos y los crímenes de guerra. Según sostiene el primer grupo, la postura predominante dentro del pensamiento occidental actual, la paz mundial puede alcanzarse a través del derecho internacional, por lo que la actuación militar de los Estados debe limitarse a la más estricta necesidad — la legítima defensa o las acciones colectivas ante situaciones excepcionales de gran riesgo-.

Dentro de esta primera corriente, la teoría legalista, se encuentran desde autores clásicos como Kant ${ }^{33}$ o Hans Kelsen (1881-1973) ${ }^{34}$, hasta contemporáneos como Jürgen Habermas ${ }^{35}$. Destaca notablemente la aportación de Habermas en esta obra, defendiendo el papel de las Naciones Unidas como órgano de encuentro y debate mundial y como ente decisorio sobre cualquier tipo de legitimación bélica.

Cabe mencionar cómo algunos autores de esta teoría argumentan que existen situaciones en las que comportamientos de los Estados dentro de sus fronteras suponen agresiones al conjunto de la comunidad internacional. El exterminio de una minoría étnica, la esclavización de un sector poblacional o la grave represión de movimientos soberanistas internos son graves violaciones de derechos humanos que generan un peligro directo para la estabilidad internacional, visto tanto desde una perspectiva moral como jurídica, en tanto que vulneran el respeto a los tratados internacionales que reconocen los derechos de los individuos. Por ello, se realiza una equiparación de este tipo de conductas con una agresión militar directa, legitimando una actuación militar de respuesta. Este grupo constituiría el punto intermedio entre la autodefensa y el intervencionismo, conformando una difusa línea que es discutida posteriormente.

En contraposición a este grupo se encuentra el sector de la teoría de la crítica radical que, a pesar de legitimar la resistencia militar frente a invasiones, rechaza cualquier tipo de institucionalización para dar respuesta a los conflictos bélicos. En su lugar, defienden que la solución a estas problemáticas internacionales debe darse desde el análisis de las realidades concretas de los Estados intervinientes, otorgando un peso mayor a los países no occidentales. Esta corriente se muestra recelosa del papel de la comunidad internacional actual como veladora de los derechos humanos, tanto por su comprensión sesgada de los derechos humanos como por una posible manipulación en beneficio de intereses particulares: consideran que el derecho internacional obedece a la consecución de intereses de los países occidentales, relegando la búsqueda de justicia a una excusa para vulnerar la soberanía de terceros Estados.

Uno de estos autores, Danilo Zolo, sostiene que la actuación internacional contra los crímenes de guerra muestra una gran ideologización: la persecución de tales

33 Immanuel Kant, Por la paz perpetua \& ¿Cómo orientarse en el pensamiento? (1795), trad. de Francisco Rivera Pastor, Ediciones Brontes, Barcelona, 2003, passim.

34 Hans Kelsen, Derecho y paz en las relaciones internacionales, trad. de Florencio Acosta, Fondo de Cultura Económica, México, 1943, passim.

35 Jürgen Habermas, El derecho internacional en la transición a un escenario posnacional, trad. de Daniel Gamper Sachse, Katz Editores, Madrid, 2008, passim. 
comportamientos depende más de los intereses geoestratégicos de las grandes potencias que de la gravedad de los crímenes cometidos. Ejemplifica esta situación a través de los Juicios de Nuremberg y a través del Tribunal Penal Internacional para los crímenes de la Antigua Yugoslavia, mostrando cómo los crímenes cometidos por determinados bandos - más concretamente los de las potencias aliadas y los de las antiguas repúblicas de Yugoslavia salvo Serbia- fueron ignorados ${ }^{36}$. Este tipo de argumentos fueron sostenidos también por Hedley Bull, quien estudia el comportamiento de las Naciones Unidas y su incapacidad para priorizar los objetivos de justicia sobre los intereses particulares ${ }^{37}$. Del mismo modo, Perry Anderson en su obra Imperium et Consilium. La política exterior norteamericana y sus teóricos estudia la evolución de Estados Unidos como potencia imperial, con especial hincapié en el desarrollo de la Guerra Fría. Sostiene, sin embargo, que tras la caída de la URSS este carácter imperial no desapareció, sino que sigue existiendo, aunque en este caso a través de las instituciones internacionales ${ }^{38}$.

\section{Intervencionismo}

Mientras que en las corrientes pacifista y de autodefensa las argumentaciones eran muy similares, divergiendo en cuestiones particulares, el intervencionismo rompe desde su misma base. En primer lugar, considera el derecho y la cooperación internacional de manera mucho más limitada: si bien entienden que pueden garantizar una relativa pacificación y cooperación entre Estados, existen situaciones en las que las instituciones, por su propia naturaleza, se muestran incapaces de dar respuestas reales y eficaces. En tales coyunturas, el recurso a la violencia no solo es una opción legítima, sino muy a menudo más efectiva, en tanto que permite una acción rápida que detenga una vulneración de derechos humanos sin tener que contar con la buena disposición del Estado agresor. En este sentido, las intervenciones militares se constituyen en una garantía del respeto a los derechos humanos y del principio de autodeterminación de los Estados, asegurando que cada comunidad disponga de su soberanía política.

Como puede observarse, hay una separación más fuerte entre pacifismo, autodefensa e intervencionismo. En esta tercera corriente ya no puede hablarse de un mayor o menor pragmatismo, sino de unas bases filosóficas diferentes: la cooperación internacional tiene límites que solo la guerra justa puede resolver eficientemente. Así, la guerra pierde su carácter completamente negativo y deja de ser el último recurso, para convertirse en la solución óptima a determinadas situaciones de la vida política internacional. En todo caso, estas diferencias no son tan intensas como en el caso del belicismo, en el que ya puede hablarse de una auténtica ruptura.

36 Danilo Zolo, La justicia de los vencedores: de Nuremberg a Bagdad, trad. de Elena Bossi, Editorial Trotta, Madrid, 2006, pp. 168-172.

37 Hedley Bull, "Order vs Justice in the International System": Political Studies, vol. 19, n. ${ }^{\circ} 3$ (1971), pp. 269283.

38 Perry Anderson, Imperium et consilium. La política exterior norteamericana y sus teóricos, trad. de Jaime Blasco Castiñeyra, Akal, Madrid, 2014, pp. 50-52. 
El intervencionismo ha sido sostenido tanto por autores clásicos como John Stuart Mill (1806-1873) ${ }^{39}$, como por contemporáneos, por ejemplo Michael Walzer ${ }^{40}$, John Rawls (1921-2002) ${ }^{41}$, o Michael Ignatieff ${ }^{42}$. No obstante, las diferencias entre estos autores son grandes, en tanto que estructuran la intervención en supuestos muy diferentes. Así, mientras que para Rawls las intervenciones se limitan a las graves violaciones de derechos humanos, Walzer incluye también la intervención en apoyo de un movimiento que se haya alzado en lucha por su independencia y la intervención contra otro Estado que se ha embarcado en una intervención militar moralmente injusta ${ }^{43}$. Por ello, este artículo considera que la realización de una tipología en la corriente intervencionista no podría reflejar la magnitud de la producción que en ella se encuentra.

Por otro lado, el pensamiento intervencionista se asienta en una serie de características comunes, que son la poca confianza en el derecho y en la cooperación internacional como mecanismos de pacificación de las relaciones internacionales y el reconocimiento de la guerra como mecanismo necesario para la protección de los derechos humanos. En estos supuestos, la acción violenta de un Estado puede ser el mecanismo más efectivo para evitar comportamientos contrarios a la moralidad general.

En primer lugar, destaca entre las características del intervencionismo que gran parte de estos autores entiende que la legitimación moral de los conflictos bélicos no tiene que provenir necesariamente de las instituciones internacionales, sino que ante situaciones de gravedad extrema existen otros métodos de justificar una intervención militar. Así, aunque la mayoría de los autores reconocen que una intervención aprobada por el Consejo de Seguridad de las Naciones Unidas es justa, no todas las intervenciones justas deben necesariamente pasar por dicho procedimiento. Por el contrario, si un Estado fuese capaz de mostrar pruebas evidentes de que se está cometiendo una limpieza étnica o genocidio, sería moralmente justo que interviniera militarmente - incluso aunque no contase con el respaldo de las Naciones Unidas-.

Para estos autores dejar de actuar ante flagrantes supuestos de violaciones de derechos humanos por no poder obtener el consentimiento de las instituciones sería un acto moralmente injustificable, pues implicaría permitir que continuara el sufrimiento de una comunidad. Defienden que el Consejo de Seguridad de las Naciones Unidas ha actuado a menudo en función de intereses geoestratégicos, vetando resoluciones en casos de evidentes crímenes de guerra y violaciones sistemáticas de derechos humanos.

Unida a la cuestión de quién puede intervenir se encuentra también la de cómo intervenir. Para esta corriente, las intervenciones militares no tienen que ser necesariamente lideradas por un gran número de Estados, tal y como ocurriría si obedeciesen a un mandato internacional de las Naciones Unidas. Por el contrario, aquellos Estados que estén en disposición de detener una grave violación de derechos humanos pueden intervenir para hacerlo, incluso aunque no logren un consenso general en la comunidad internacional. Desde el punto de vista de Walzer, intervenciones unilate-

39 John Stuart Mill, “A Few Words on Non-Intervention” (1849): Foreign Policy Perspectives, n. ${ }^{\circ} 8$ (1987), pp. 2-6.

40 Walzer, Just and Unjust Wars, pp. 86-109.

${ }^{41}$ John Ralws, El derecho de gentes, trad. de Hernando Valencia Villa, Editorial Paidós, Madrid, 2001, passim.

42 Michael Ignatieff, Virtual War: Kosovo and Beyond, Penguin Books, Londres, 2000, passim.

43 Walzer, Just and Unjust Wars, p. 90. 
rales tan exitosas como la de Vietnam en Camboya en 1979 o la de India en Pakistán en protección de la población de Bangladesh en 1971 muestran que, en ocasiones, las intervenciones llevadas a cabo por países vecinos generan menor rechazo y tienen mayor éxito que grandes coaliciones internacionales. Cuestiones como el lenguaje común o el conocimiento de las tradiciones de las poblaciones invadidas pueden implicar una mejor comprensión por su parte de que no están siendo conquistadas por una fuerza extranjera.

Una vez expuesto el concepto y características de esta corriente, y dadas las similitudes entre esta postura y la conocida como de la autodefensa, a continuación se exponen las principales diferencias entre ambos criterios, mostrando la interacción y crítica de ambos pensamientos. En primer lugar, el intervencionismo considera a las instituciones internacionales con mucha menor capacidad de resolución de conflictos que los autores que limitan el uso de la violencia a la autodefensa. Para estos últimos, es posible evitar la mayoría de los conflictos entre Estados y reconducir a aquellos que lleven a cabo conductas intolerables, de tal manera que las intervenciones humanitarias son totalmente residuales, quedando para supuestos de Estados con los que la presión o el diálogo internacional es totalmente imposible. Por el contrario, para gran parte del pensamiento intervencionista las instituciones internacionales actuales, especialmente las Naciones Unidas a través de su Consejo de Seguridad, son incapaces de resolver algunos de los problemas más acuciantes de la esfera internacional. Así, existen determinadas situaciones, como el exterminio o la limpieza étnica de una minoría, en las que la intervención militar de un Estado es la única vía para alcanzar una solución lo suficientemente rápida y efectiva como para suponer una respuesta real a tales desafíos a la paz y a la seguridad internacional.

En segundo lugar, para el intervencionismo el cumplimiento de una serie de requisitos formales, como serían la aprobación por parte del Consejo de Seguridad, no es un requisito tan importante como lo es para la autodefensa ${ }^{44}$. Por el contrario, aunque las instituciones son una forma de demostrar que existe cierto consenso sobre la intervención, existen otra serie de intervenciones legítimas, desde la de una coalición de Estados hasta la actuación unilateral, en las que aquel Estado que pueda intervenir de manera efectiva para poner fin a graves violaciones de derechos humanos y tenga disposición de hacerlo está moralmente legitimado.

En tercer lugar, la autodefensa diverge del intervencionismo en la diferente concepción de la violencia dentro de las relaciones entre Estados. Mientras que para el primero la violencia representa el fracaso constatado de la comunidad internacional, para el intervencionismo constituye un elemento necesario para la resolución de conflictos que no pueden abordarse a través de mecanismos institucionales. En este sentido, las intervenciones militares, desligadas de cualquier organización internacional, proporcionan una herramienta imprescindible para proteger a comunidades que se enfrentan a un riesgo extremo porque proveen de una respuesta rápida y eficaz imposible de alcanzar por otras vías más institucionales.

En cuarto lugar, el intervencionismo va más allá de la legitimación de la violencia como respuesta a una agresión previa, puesto que también la justifica

44 Más concretamente dentro de la autodefensa se exige la aprobación de la intervención en el Consejo de Seguridad, mientras que el intervencionismo no acepta esta limitación formal: una intervención es legítima o no con independencia de las instituciones, que en ocasiones funcionan de manera muy ineficiente. Este es uno de los elementos de fricción entre autodefensa e intervencionismo más interesantes y de mayor calado. 
moralmente en otra serie de supuestos destinados a la protección de los derechos de los individuos o del derecho a la autodeterminación de los pueblos. Por tanto, no se justifica en la protección de la comunidad internacional frente a una agresión abstracta, sino que lo hacen con base en la inmoralidad de los comportamientos que se pretende evitar y del error que sería dilatar innecesariamente la intervención. De hecho, incluso esto lleva a considerar algunos tipos de legítima defensa que serían rechazados por las posturas de la autodefensa, como pueden ser la preventive war - guerra preventiva- o la preemptive war - guerra anticipatoria-.

Con respecto a estos conceptos, George Fletcher y Jens David Ohlin desarrollan la distinción entre excusar y justificar una intervención y muestran las situaciones en las que la autodefensa puede conducir a las invasiones militares incluso cuando no ha existido un ataque previo ${ }^{45}$. Estos autores podrían ubicarse dentro de esa frontera difusa entre la autodefensa y el intervencionismo, al desarrollar el derecho de defensa de un Estado en situaciones que se solapan con la intervención militar. Por último, como ya se mencionó anteriormente, existe un cambio cualitativo entre las bases filosóficas del intervencionismo con respecto a la continuidad entre el pacifismo y la autodefensa. Con el propósito de mostrar esta ruptura, a continuación se desarrolla la crítica que Michael Walzer realizó al pacifismo en el prefacio a la tercera edición de su obra Just and Unjust Wars - y que en cierta medida podría ser extendido a la autodefensa ${ }^{46}$ -

El primer aspecto que Walzer critica del pacifismo es la posibilidad de encontrar un método de presión no violento que permita responder de manera efectiva a situaciones de agresión y conquista del territorio frente a un enemigo, tanto nacional como extranjero. El objetivo de estas actuaciones sería mostrar el rechazo de la comunidad al Estado, así como desestabilizar política y económicamente al gobierno, presumiendo que el enemigo se irá viendo presionado de manera creciente hasta que las condiciones para mantener la conquista sean tan extremas que deban abandonar el territorio ocupado.

Ante este tipo de propuestas Walzer encuentra una serie de problemas organizativos insalvables: dentro de naciones reprimidas, bien por un gobierno nacional, bien por uno extranjero, el capital social y la tradición de participación y organización probablemente se encuentren gravemente deteriorados, por lo que resultaría muy difícil alcanzar y mantener en el medio-largo plazo la movilización de miles de individuos para llevar a cabo huelgas o manifestaciones, teniendo en cuenta la represión a la que se pueden exponer.

Además, Walzer también critica las expectativas humanistas del pacifismo: que, frente a estas actividades de resistencia, las respuestas de las autoridades sean en cierta medida proporcionales y respeten los derechos básicos de, por ejemplo, los manifestantes. En este sentido, el pacifismo supone que el gobierno opresor comparte el mismo sistema de valores que aquellos que llevan a cabo la resistencia pacífica. Desafortunadamente, la historia ha dado numerosos casos en los que esto no ha sido así, cuando la represión extrema paralizó totalmente este tipo de resistencia, ya que hizo imposible el sostenimiento de las acciones no violentas —obligando a los grupos contrarios al gobierno a optar por métodos más clásicos, como serían las gue-

45 George Fletcher y Jens David Ohlin, Defending Humanity: When Force is Justified and Why, Oxford University Press, Oxford, 2008, pp. 127-128.

46 Se ha optado por incluir la crítica de Michael Walzer por ser uno de los pensadores contemporáneos que más intensamente ha trabajado la teoría de la guerra justa. Por ello mismo su trabajo también es estudiado en su crítica al realismo, parte de la corriente del belicismo. 
rrillas urbanas ${ }^{47}$ - En sus propias palabras, la lucha no violenta: "sometida a condiciones extremas, degenera en una violencia dirigida contra uno mismo en vez de constituirse en violencia contra cualquiera de los que pretenden asesinarle a uno"48.

Por tanto, para Walzer los planteamientos de resistencia no violenta pueden resultar exitosos solamente contra oponentes que mantengan un mismo sistema de valores que respete la integridad de aquellos que se manifiestan sin emplear la violencia. Pero cuando las autoridades estén dispuestas a recurrir a medidas extremas de represión, la acción no violenta se ve totalmente sobrepasada. Como respuesta, ha sido frecuente que autores pacifistas planteen una revisión histórica del éxito que la resistencia pacifista ha tenido, incluso con gobiernos con muy elevada represión ${ }^{49}$.

De hecho, este tipo de críticas son a menudo consideradas como fruto de un exceso de pragmatismo que considera que la violencia es el elemento último de las relaciones interpersonales, renunciando a defender el empoderamiento de la sociedad civil. Además, asumir la violencia como inherente a la esencia humana supone dejar de plantear propuestas más ambiciosas de pacificación de las relaciones internacionales: la producción pacifista no solo consiste en proponer propuestas no violentas, sino en plantear que estas sean posibles.

\section{Belicismo}

En último lugar, se encontraría la corriente belicista, que cuenta con una larga tradición histórica ya desde la Antigua Grecia, con autores como Tucídides con su obra Historia de la Guerra del Peloponeso. Dentro del belicismo se engloban a todas aquellas posturas que niegan los límites al uso de la guerra por parte de los Estados de forma permanente, llegando en algunos casos a rechazar incluso la idoneidad de las valoraciones morales en los conflictos bélicos. Ya sea por los efectos que la renuncia al uso de la violencia pueda generar, bien por sostener concepciones bélicas de la naturaleza humana, o incluso directamente por negar la posibilidad de valorar moralmente conflictos bélicos, todas ellas coinciden en la negativa a renunciar a la soberanía de los Estados sobre la guerra.

Como puede observarse, la ruptura del belicismo con respecto al resto de corrientes es total, tanto desde los puntos de partida como de las perspectivas de la comunidad internacional. Mientras que las posturas estudiadas hasta este punto tenían unas ciertas expectativas de pacificación de las relaciones internacionales —más en el pacifismo y la autodefensa que en el intervencionismo - el belicismo directamente asume la inevitabilidad del conflicto militar en la esfera internacional: los Estados actuarán en sus relaciones internacionales por los mecanismos necesarios para alcanzar sus intereses. Además, consideran que esta máxima es inmutable, puesto que al margen de los acuerdos que alcancen, en última instancia se primará la búsqueda de los intereses particulares — sean estos económicos, políticos o simplemente de seguridad-.

47 Según este autor, esto explica por qué no existieron auténticos movimientos pacifistas frente a dictaduras que recurrían sistemáticamente al uso de la violencia, como la Alemania de Adolf Hitler (1889-1945).

48 Michael Walzer, Guerra, política y moral, trad. de Tomás Fernández Aúz y Beatriz Eguibar, Editorial Paidós, Barcelona, 2001, p. 8.

49 Gene Sharp, From Dictatorship to Democracy, The Albert Einstein Institution, East Boston, 2010, pp. 25-29. 
De esta concepción tan pesimista de las relaciones internacionales - $\mathrm{o}$ realista desde su punto de vista - se derivan unas expectativas muy bajas para la comunidad internacional, puesto que en última instancia no van a poder evitar los conflictos entre Estados. Y el efecto de toda esta base filosófica es el rechazo a la teoría de la guerra justa, puesto que la moralidad no desempeña ningún papel relevante en la toma de decisiones de los conflictos entre Estados: la moralidad será parte, como máximo, de un constructo argumentativo que servirá para justificar las decisiones previamente tomadas.

Por otro lado, esta cuarta corriente se caracteriza por rechazar - parcial o totalmente - la limitación moral de los conflictos bélicos, ya sea por la naturaleza de la guerra, de los individuos que participan en ellos, o por la prevalencia de otra serie de argumentaciones centradas en la razón de Estado. Más concretamente pueden distinguirse tres rasgos: la concepción de la esfera internacional como un ámbito de conflicto militar entre Estados, la imposibilidad de eliminar tales conflictos entre los Estados y la inevitabilidad de la guerra como mecanismo de resolución de conflictos.

En primer lugar, estos autores coinciden en una cierta comprensión de la naturaleza como una competición entre Estados que, si bien no implica necesariamente conflictos violentos, sí genera inercias para que estos finalmente tengan lugar. Además, cuando finalmente suceden, esta naturaleza hace que los combates se eleven de manera exponencial, sumergiendo a las partes en una vorágine de muerte y destrucción cada vez mayor. Resulta llamativo que en este punto belicismo y pacifismo lleguen a conclusiones parecidas, pues ambos comparten esa creencia hacia el crecimiento exponencial de los conflictos bélicos. Sin duda evidencia la influencia del pensamiento de Clausewitz en el pensamiento occidental contemporáneo.

En segundo lugar, estos autores consideran que los conflictos bélicos entre Estados son inherentes a las propias relaciones internacionales, como parte esencial e irrenunciable de su capacidad política. En este sentido, la guerra es una parte de la política que todo dirigente de un Estado debe tomar en consideración ${ }^{50}$. En tanto que cada Estado persigue intereses particulares, se ven tentados a aprovecharse de las relaciones de poder que pueda tener con respecto a otros, lo que genera una esfera internacional necesariamente violenta y basada en la imposición de unos Estados sobre otros. Por todo ello, el belicismo describe un mundo en el que los Estados compiten de manera constante, siempre dispuestos a emprender conflictos si de ellos pueden obtener beneficios suficientes, lo que en última instancia genera un clima de recelo y resentimiento que hace imposible propuestas de limitación de la disposición a la violencia entre los Estados. De hecho, dentro de estos intereses también debe entenderse la propia seguridad, pues la inseguridad —así como la percepción de inseguridad - es un importante catalizador de conflictos.

Centrados en la tipología de esta categoría, en el belicismo no existe una homogeneidad entre sus autores, puesto que estos estudian diferentes aspectos de los conflictos bélicos y a menudo desde planteamientos antagónicos. No obstante, es posible diferenciar entre belicismo total y belicismo parcial, dependiendo del grado de rechazo que se haga de la moralidad en los conflictos bélicos: mientras que el primero, representado por el realismo político, niega la legitimidad de las valora-

50 De nuevo la influencia de Clausewitz y su concepción de la guerra como parte de la vida política es clara. Carl von Clausewitz, De la guerra (1832), Editorial Mateu, Barcelona, 1972, passim. 
ciones morales dentro de los conflictos bélicos; las posturas del segundo aceptan las valoraciones morales, aunque no en toda su extensión.

En primer lugar, dentro de la postura del rechazo total podría situarse a la generalidad de los autores del conocido como realismo político, en tanto que directamente niegan la viabilidad de los juicios morales en asuntos concernientes a conflictos bélicos y relaciones internacionales, abogando en su lugar por acercamientos de otra índole más material y objetiva. Dentro de estos autores se encuentran tanto clásicos como Nicolás Maquiavelo (1469-1527) ${ }^{51}$ y Thomas Hobbes (1588-1679) ${ }^{52}$, como modernos, destacando Hans Morgenthau (1904-1980) ${ }^{53}$ o John Mearsheimer ${ }^{54}$. Desde esta postura, el recurso a la violencia es una herramienta más dentro de la resolución de controversias entre Estados, y, como tal, debe regirse por consideraciones políticas.

Según esta teoría, tanto en la iniciación como en el desarrollo de un conflicto bélico, los factores determinantes se encuentran desligados de consideraciones éticas, quedando el ámbito moral restringido a una esfera eminentemente instrumental. De estos autores pueden extraerse una serie de consideraciones comunes que todos ellos comparten: la creencia de que de manera natural entre Estados independientes reina la anarquía y el conflicto, la consideración de que el principio que rige la política internacional es el estado de guerra y una visión escéptica hacia cualquier tipo de esquema que tienda a pacificar y equiparar el orden internacional.

De acuerdo a Michael Doyle, uno de los escritores más prominentes en la teoría de las relaciones internacionales contemporáneas, "[e]1 realismo... es nuestra teoría más distintiva, la teoría que, para alguno, promete una explicación de la política internacional basada en nada más y nada menos que la anarquía de las mismísimas relaciones internacionales" 55 .

De hecho, de esta misma consideración nace una de las críticas más fuertes, desarrollada por este mismo autor: al tomar una serie de consideraciones acerca de los individuos y los Estados - la agresividad y la búsqueda de poder - y elevarlos a una categoría natural del ser, proporciona la justificación teórica para ese tipo de conductas, con lo que en última instancia se generan dinámicas de legitimación recíproca. Sin embargo, la existencia de estas inercias no implica necesariamente que sea por un elemento intrínseco al ser humano, por lo que podrían ser sustituidas por otro tipo de valores y relaciones entre Estados.

Por otro lado, con respecto al belicismo parcial, aquellas posturas que limitan parcialmente las valoraciones morales dentro de la guerra, tomando en consideración la dicotomía clásica de la teoría de la guerra justa, puede distinguirse entre los que defienden la soberanía absoluta de los Estados sobre su capacidad para decidir el inicio de los conflictos armados, el ius ad bellum, y entre los que rechazan cualquier limitación a los comportamientos dentro de estos, el ius in bello. Algunos de los prin-

51 Nicolás Maquiavelo, El príncipe (1513), trad. de Francisco Javier Alcántara, Planeta, Madrid, 1992, passim.

52 Thomas Hobbes, Leviatán, o la materia, forma y poder de una república eclesiástica y civil (1651), trad. de Carlos Mellizo, Altaya, Barcelona, 1997, passim.

53 Hans Morgenthau, Politica entre las naciones: la lucha por el poder y la paz (1948), trad. de Heber Olivera, Grupo Editor Latinoamericano, Buenos Aires, 1986, passim.

54 John Mearsheimer, The Tragedy of Great Power Politics, W.W. Norton \& Company, New York, 2001, passim.

55 "Realism...is our most distinctive theory, the theory that, for some, promises an explanation of international politics grounded in nothing below or beyond the anarchy of interstate relations itself". Michael Doyle, Ways of War and Peace: Realism, Liberalism, Socialism, Editorial Norton and Company, New York, 1997, p. 41. 
cipales autores de este grupo serían Carl Schmitt (1888-1985), Clausewitz, William Tecumseh Sherman (1820-1891) o Gueorgui Zhúkov (1896-1974).

Con el propósito de explicar esta distinción - a la vez que mostrar las diferencias que pueden existir dentro de la corriente del belicismo - se desarrolla brevemente la teoría de dos autores que representan cada una de las dos posibilidades del belicismo parcial en la disposición de los conflictos bélicos: Sherman, estudiado a través de sus Memorias $^{56}$, y a quien se le atribuye ser el padre de la guerra moderna, y Schmitt, uno de los pensadores más polémicos del siglo veinte, entre otros aspectos por su concepción del ius publicum europaeum, descrito en su obra El nomos de la tierra. Ambos autores destacan por sus posiciones totalmente antagónicas con respecto a la concepción de la guerra: mientras que el primero muestra un rechazo absoluto, por considerarla causante de la miseria humana, el segundo lo entiende como parte necesaria y fundamental de la naturaleza humana.

En primer lugar, para Sherman, un famoso general americano que luchó en el bando unionista en la Guerra Civil Americana, dicho conflicto suponía el mayor de los males posibles, puesto que había conducido a una confrontación entre hermanos que se estaba cobrando miles de vidas cada día, sembrando el país entero de pobreza, hambruna y enfermedad. Irónicamente, bajo la proclama de "la guerra es crueldad. No sirve reformarla; cuanto más cruel sea, más pronto terminará" 57 , Sherman introdujo la llamada estrategia de la Guerra Total, por la cual legitimó actuaciones que contravenían los deberes morales que hasta ese momento habían imperado: bombardeó a la población civil, practicó tierra quemada, destruyó sistemáticamente la infraestructura confederada, etc. Con estas prácticas, que ignoraban cualquier tipo de reconocimiento de ius in bello, Sherman pretendía lograr la derrota del bando confederado y poner fin a la guerra lo más pronto posible.

Por el contrario, Schmitt ${ }^{58}$ creció durante un periodo de gran convulsión política, con el estallido de la Primera Guerra Mundial, el nacimiento de la Unión Soviética, la creación y el fracaso de la Sociedad de Naciones y, por último, la Segunda Guerra Mundial. Toda esta inestabilidad y violencia cabe suponer que influyese en su pensamiento, haciéndole receloso hacia cualquier sistema que tratase de resolver y evitar los conflictos bélicos a través de la cesión de soberanía por parte de los Estados.

No obstante, la comprensión del pensamiento schmittiano y su negación del ius ad bellum debe contextualizarse dentro de una de sus quizás mayores aportaciones, la crítica al pensamiento juridicista, según la cual el derecho internacional y la cooperación entre Estados pueden reconducir los conflictos militares, de tal manera que impere la paz y el respeto a los derechos humanos. Para ello, Schmitt hace una reconstrucción histórica de Europa, observando cómo una serie de conflictos internos fue progresivamente dando paso a la lucha contra terceros como elemento cohesionador.

56 William Tecumseh Sherman, Memoirs (1875), Da Capo Press, Boston, 1984, passim.

57 "War is cruelty. There is no use trying to reform it; the crueler it is, the sooner it will be over". Norma Risjord, Representative Americans. The Civil War Generation, Roman \& Littlefield Publishers, New York, 2002, p. 143.

58 Dado lo particular de la teoría de Schmitt sobre esta cuestión, se ha optado por dedicarle un estudio más pormenorizado. Así, se muestra la estructura filosófica-argumentativa que defiende la defensa parcial de los análisis normativos de los conflictos bélicos. 
Sin embargo, aunque se había superado el hobbesiano estado de naturaleza a nivel individual, existía una reproducción de esa misma situación a nivel internacional, puesto que estos se encuentran ante una multiplicidad de conflictos violentos ante los cuales no existe ningún tipo de autoridad que los limite. Por ello, de cara a evitar el estado de guerra constante, emerge el derecho internacional en base al principio de unidad cristiana - Res Publica Cristiana - limitando el comportamiento bélico, aunque manteniendo el derecho a iniciar y terminar la guerra, que quedaba ligada a la figura del soberano: este es el que Schmitt denomina ius publicum europaeum ${ }^{59}$. Así se logró la limitación de la guerra que von Clausewitz ya describió: la reducción de los objetivos, la cada vez menor necesidad de uso de la violencia y, por ende, el paulatino reconocimiento del enemigo como parte de la misma comunidad internacional.

Partiendo de esta descripción de cómo pudo limitarse en Europa la guerra entre Estados a través de la propia normalización de esta, Schmitt argumenta su crítica al denominado pacifismo: esta visión, aunque busca la defensa de la paz y la reducción de los conflictos entre Estados, no hace sino aumentarlos, tanto en el número como en la virulencia de estos. La ideología liberal, al buscar unos objetivos de tan elevada altura moral, rompe con lo que hasta ese momento había sido el principal garante del ius in bello en Europa, la relativización de las fuerzas a causa de lo limitado de los objetivos.

Si bien para una guerra de fronteras o sucesiones los Estados no van a destinarse una cantidad elevada de sus recursos, si lo que está en juego es la consecución de la paz mundial y el respeto a los derechos humanos, las naciones no dudarán en dedicar a tal empresa todas sus fuerzas y cruzar todos los límites morales que sean necesarios. Por tanto, lo ambicioso de los objetivos de las guerras humanitarias provocó un aumento cuantitativo y cualitativo de estas. Además, puesto que quien emprende una guerra en busca de la paz mundial está defendiendo en última instancia la culminación de la humanidad, el enemigo que evita esta consecución se erige en un enemigo de la humanidad que no merece ningún tipo de reconocimiento por parte de sus enemigos. Por ello, así se rompe el reconocimiento del enemigo como parte esencial en la definición de uno mismo - el pilar principal de la limitación de la guerra en el ius publicum europaeum-.

Estos autores muestran cómo existen toda una serie de pensadores que recelan de las limitaciones morales a los conflictos bélicos, ya sea porque consideran que el perjuicio de la guerra es tan elevado que cualquier límite interno no hace sino extender su final, o porque la reducción de la soberanía estatal para iniciar conflictos bélicos degenera en una deshumanización de aquellos que se oponen a la ideología humanitaria. De hecho, mientras que Schmitt efectivamente negaría la validez de las valoraciones morales dentro de los conflictos bélicos, por llevar a una deshumanización del enemigo, para Sherman estas eran parte fundamental de sus creencias, puesto que era la inmoralidad de la guerra la que legitimó todas sus actuaciones.

Por otro lado, con el fin de mostrar la tensión que generan las concepciones belicistas al negar la posibilidad de hacer valoraciones morales, a continuación se expone la crítica de Michael Walzer al realismo, que se englobaría dentro del belicismo total, al que acusa de promover un "determinismo interesado". Así, la crítica de Walzer puede resumirse en la negación de la inevitabilidad de que los Estados persi-

59 Schmitt, El nomos de la tierra en el Derecho de Gentes, p. 132. 
gan sus intereses particulares. De hecho, cabe destacar la similitud entre esta crítica y la teoría sobre la violencia de Hannah Arendt (1906-1975), que considera el poder como separado de la violencia y la imposición de unos individuos o Estados sobre $\operatorname{otros}^{60}$. Aunque lo hagan desde distintas perspectivas, ambos autores defienden la importancia de la moralidad en los conflictos bélicos frente a concepciones realistas, mostrando cómo la discusión moral sí permite el desarrollo de una teoría normativa propiamente dicha. En este sentido Walzer afirma que la realidad moral de la guerra no es una construcción objetiva y externa al hombre, sino que viene determinada por la valoración y percepción del conjunto de la humanidad. En cada uno de los conflictos que tienen lugar en nuestro mundo existen enfoques y comportamientos distintos, lo que implica que existió una determinación concreta con base en esos significados ${ }^{61}$.

En estas valoraciones, los argumentos de justicia que se aplican no lo hacen en un contexto tan abierto como exponen los autores del realismo - que los entienden como herramientas para justificar sus decisiones interesadas-, sino que exigen una concatenación de argumentos basados unos en otros. Por tanto "el discurso moral es coercitivo: una cosa lleva a la otra...Una guerra injusta...lo es porque se rechaza por razones concretas y cualquiera que comparta la desaprobación deberá proporcionar evidencias concretas de por qué lo hace" ${ }^{62}$. Esta necesidad de justificación implica la inmersión en una esfera discursiva en la que cada nueva aportación debe basarse en lo expuesto con anterioridad, constituyendo una coherente construcción argumentativa.

Por tanto, Walzer realiza una crítica a todo pensamiento que trata de limitar la guerra a una lucha de poder en la que individuos y Estados se ven sujetos al determinismo de la búsqueda de sus intereses y, por ende, a la apatía moral con respecto a estos comportamientos. Retomando a Arendt: “[n]ada, en mi opinión, podría ser teóricamente más peligroso que la tradición de pensamiento orgánico en cuestiones políticas, por la que el poder y la violencia son interpretados en términos biológicos"63.

Por el contrario, estos autores proponen unas argumentaciones sobre la inherencia de los juicios morales y sobre la existencia de nexos valorativos comunes a todas las culturas a través del cual exponer una teoría moral sobre los conflictos bélicos.

\section{Conclusiones}

Con esta clasificación se ha mostrado cómo es posible distinguir diferentes posturas en la teoría de la guerra justa en función la disposición de la guerra por parte de los Estados. De cara a poder tener una visión global de la aportación que este criterio supone, a continuación se muestra una tabla en la que se resumen las características de cada una de las principales corrientes expuestas: cómo conciben las relaciones internacionales, qué papel desempeña la guerra en dichas relaciones y por qué métodos de resolución de controversias se inclinan respuestas a cada una de ellas.

60 Hannah Arendt, Sobre la violencia (1970), trad. de Guillermo Solana, Alianza Editorial, Madrid, 2006, passim.

61 Walzer, Just and Unjust Wars, pp. 30-35.

62 "Moral talk is coercive; one thing leads to another...A war called unjust...is a war misliked for particular reasons, and anyone making the charge is required to provide particular sorts of evidence". Ibid., p. 12.

63 Arendt, Sobre la violencia, pp. 101-102. 


\begin{tabular}{|c|c|c|c|c|}
\hline & Pacifismo & Autodefensa & Intervencionismo & Belicismo \\
\hline $\begin{array}{c}\text { Concepción de las } \\
\text { relaciones entre } \\
\text { Estados }\end{array}$ & $\begin{array}{c}\text { Cooperación y } \\
\text { mutuo beneficio }\end{array}$ & $\begin{array}{c}\text { Cooperación y } \\
\text { mutuo beneficio }\end{array}$ & $\begin{array}{c}\text { Cooperación y } \\
\text { competición }\end{array}$ & Competición \\
\hline $\begin{array}{c}\text { Concepción } \\
\text { de la guerra }\end{array}$ & $\begin{array}{c}\text { Absolutamente } \\
\text { negativa }\end{array}$ & $\begin{array}{c}\text { Negativa pero } \\
\text { justificable para la } \\
\text { supervivencia }\end{array}$ & $\begin{array}{c}\text { Negativa pero } \\
\text { justificable e } \\
\text { incluso una } \\
\text { solución óptima } \\
\text { en determinadas } \\
\text { ocasiones }\end{array}$ & $\begin{array}{c}\text { Necesaria e } \\
\text { inevitable }\end{array}$ \\
\hline $\begin{array}{c}\text { Método de solución } \\
\text { de controversias }\end{array}$ & Siempre pacíficos & $\begin{array}{c}\text { Pacíficos salvo en } \\
\text { defensa frente a } \\
\text { agresión }\end{array}$ & $\begin{array}{c}\text { Alternativamente } \\
\text { pacíficos o bélicos, } \\
\text { dependiendo de la } \\
\text { situación }\end{array}$ & $\begin{array}{c}\text { Inevitablemente } \\
\text { bélico }\end{array}$ \\
\hline
\end{tabular}

Tabla 1. Comparativa entre los enfoques y las preguntas de la propuesta de criterio de clasificación.

Como puede observarse, esta clasificación provee una visión general que permite un acercamiento al conjunto de la teoría de la guerra justa desde una perspectiva moral. Frente a las corrientes centradas en aspectos filosóficos alejados de la realidad práctica, la disposición al uso de la violencia por parte de los Estados propone una aproximación con el potencial de mostrar los argumentos de los principales autores de la teoría política sobre conflictos actuales, favoreciendo un acercamiento entre teoría y práctica.

En segundo lugar, esta clasificación aporta un método para distinguir una serie de categorías sobre las que han existido importantes debates. Comenzando con el intervencionismo y la autodefensa, se propone como eje diferenciador la naturaleza de la invasión: o un acto de defensa colectiva en casos de comportamientos que ponen en riesgo a la sociedad internacional o si una respuesta contra determinados comportamientos contrarios a los derechos humanos más fundamentales. Del mismo modo, la distinción entre las dos vertientes del pacifismo, emotivo y racional, permite diferenciar según el tipo de rechazo a la violencia, en función de si lo hacen por la inmoralidad del comportamiento en sí mismo o incluyen también cuestiones más materiales. Por último, la distinción entre el rechazo parcial o absoluto de las limitaciones morales dentro del belicismo muestra el contraste entre quienes rechazan la teoría de la guerra justa por negar la moral en la valoración de los conflictos armados, respecto de aquellos que refutan su validez en ciertas áreas concretas.

En tercer lugar, la presente conceptualización señala la existencia de una cierta correlación entre la concepción de la guerra dentro de la naturaleza humana y la legitimación que hacen del uso de esta: mientras que los autores realistas que entienden la guerra como inherente al ser humano legitiman un mayor uso de la violencia, aquéllas con valores más liberales tienden a limitarlo hacia posturas más defensivas. Así, puede distinguirse la existencia de polos en conflicto, entre las concepciones belicistas que consideran la guerra como parte esencial del ser humano, frente a liberales que tratan de limitarla todo lo posible. Por tanto, en última instancia las diferentes posturas sobre la legitimidad de los conflictos militares no se limitan a la 
consideración de la disposición de la guerra, sino que en enraízan con concepciones sobre la naturaleza del hombre.

Por último, se ha profundizado en la interacción entre las distintas corrientes, mostrando los puntos en común, así como las críticas que desde unas dirigen a otras. Destaca en primer lugar la vinculación entre pacifismo, autodefensa e intervencionismo, reflejando cómo existen determinados valores comunes (especialmente entre los dos primeros) que varían en intensidad en cada una de ellas. Del mismo modo, las críticas cruzadas entre tales corrientes muestran por un lado la importancia del componente filosófico en la teoría de la guerra justa — véase cómo la discusión entre belicismo y pacifismo hunde sus raíces en la concepción violenta (o no) del hombre - y por otro la existencia de un interesante debate para la teoría política, tanto para desarrollar dichas críticas como para tratar de afrontarlas.

\section{Referencias bibliográficas}

Ackerman, Peter y Kruegler, Chris, Strategic Nonviolent Conflict: The Dynamics of People Power in the Twentieth Century, Praeger, Westport, 1994.

Anderson, Perry, Imperium et consilium. La politica exterior norteamericana y sus teóricos, trad. de Jaime Blasco Castiñeyra, Akal, Madrid, 2014.

Arendt, Hannah, Sobre la violencia (1970), trad. de Guillermo Solana, Alianza Editorial, Madrid, 2006.

Beavouir, Simone de, El segundo sexo (1949), trad. de Pablo Palant, Editorial Siglo Veinte, Buenos Aires, 1969.

Brock, Peter, The Quaker Peace Testimony 1660 to 1914, Sessions Book Trust, New York, 1990.

Bull, Hedley, “Order vs Justice in the International System": Political Studies, vol. 19, n. 3 (1971), pp. 269-283.

Clausewitz von, Carl, De la guerra (1832), Editorial Mateu, Barcelona, 1972.

Doyle, Michael, Ways of War and Peace: Realism, Liberalism, Socialism, Editorial Norton and Company, New York, 1997.

Femenías, María Luisa, "Pacifismo, feminismo y utopía": Daimon. Revista Internacional de Filosofía, n. ${ }^{\circ} 4$ (2011), pp. 45-58.

Fletcher, George y Ohlin, Jens David, Defending Humanity: When Force is Justified and Why, Oxford University Press, Oxford, 2008.

Gallagher Cunningham, Kathleen, "Understanding Strategic Choice: The Determinants of Civil War and Nonviolent Campaign in Self-determination Disputes": Journal of Peace Research, vol. 50, n. ${ }^{\circ} 3$ (2013), pp. 291-304.

Glover Jonathan, Humanity: A Moral History of Twentieth Century, Yale University Press, New Haven, London, 2013.

Habermas, Jürgen, El derecho internacional en la transición a un escenario posnacional, trad. de Daniel Gamper Sachse, Katz Editores, Madrid, 2008.

Hessel, Stéphane, iIndignaos!, trad. de María Belvis Martínez García, Destino, Barcelona, 2011.

Hobbes, Thomas, Leviatán, o la materia, forma y poder de una república eclesiástica y civil (1651), trad. de Carlos Mellizo, Altaya, Barcelona, 1997.

Holmes, Robert L., On War and Morality, Princeton University Press, Princeton, 2014. 
Ignatieff, Michael, Virtual War: Kosovo and Beyond, Penguin Books, London, 2000.

Kamen, Henry, "Las paradojas del pacifismo". Disponible en: http://personales.upv. es/ jvoltra/textos/textostem/pacifismo.htm (23-6-2017).

Kant, Immanuel, Idea para una historia universal en sentido cosmopolita (1784), trad. de Concha Roldán Panadero y Roberto Rodríguez Aramayo, Tecnos, Madrid, 1994.

- Por la paz perpetua \& ¿Cómo orientarse en el pensamiento? (1795), trad. de Francisco Rivera Pastor, Ediciones Brontes, Barcelona, 2003.

Kelly, Petra, Fighting for Hope, Chatto \& Windus, London, 1984.

Kelsen, Hans, Derecho y paz en las relaciones internacionales, trad. de Florencio Acosta, Fondo de Cultura Económica, México, D.F., 1943.

King, Martin Luther, Jr., Strength to Love, Editorial Collins, London, 1963.

- "Beyond Vietnam", en A Call to Conscience: The Landmark Speeches of Martin Luther King, Jr., ed. de Clayborne Carson, IPM/Warner Books, New York, 2001.

López Martínez, Mario, "La sociedad civil por la paz", en Historia de la paz: tiempos espacios y actores, Universidad de Granada, Granada, 2000, pp. 328-329.

MacIntyre, Alasdair, Tras la virtud, trad. de Amelia Valcárcel, Crítica, Barcelona, 1988.

Mann, Michael, Las fuentes del poder social, trad. de Fernando Santos Fontenla, Alianza Editorial, Madrid, 1991.

Maquiavelo, Nicolás, El príncipe (1513), trad. de Francisco Javier Alcántara, Planeta, Madrid, 1992.

Mearsheimer, John, The Tragedy of Great Power Politics, W.W. Norton \& Company, New York, 2001.

Mill, John Stuart, “A Few Words on Non-Intervention” (1849): Foreign Policy Perspectives, n. ${ }^{\circ} 8$ (1987), pp. 2-6.

Morgenthau, Hans, Política entre las naciones: la lucha por el poder y la paz (1948), trad. de Heber Olivera, Grupo Editor Latinoamericano, Buenos Aires, 1986.

Pateman, Carole, The Sexual Contract, Stanford University Press, Stanford, 1988.

Ralws, John, El derecho de gentes, trad. de Hernando Valencia Villa, Editorial Paidós, Madrid, 2001.

Risjord, Norma, Representative Americans. The Civil War Generation, Roman \& Littlefield Publishers, New York, 2002.

Schmitt, Carl, El nomos de la tierra en el Derecho de Gentes del "Ius publicum europaeum" (1950), trad. de Dora Schilling Thon, Centro de Estudios Políticos y Constitucionales, Madrid, 1979.

Sharp, Gene, y Paulson, Joshua, Waging Nonviolent Struggle: 20th Century Practice and 21st Century Potential, Extending Horizons Books, Boston, 2005.

Sharp, Gene, Exploring Nonviolent Alternatives, Porter Sargent, Boston, 1970.

—, The Politics of Nonviolent Action, Porter Sargent, Boston, 1973.

—, From Dictatorship to Democracy, The Albert Einstein Institution, East Boston, 2010.

Sherman, William Tecumseh, Memoirs (1875), Da Capo Press, Boston, 1984.

Sibley, Mulford, (ed.), The Quiet Battle: Writings on the Theory and Practice of Non-violent Resistance, Beacon Press, Boston, 1963.

Trotsky, Leon, Pacifism as the Servant of Imperialism, Communist International, New Series, n. ${ }^{\text {o }} 5$ (1917). Disponible en: https://www.marxists.org/archive/trotsky/1917/xx/pacifism. htm (23-6-2017).

Walzer, Michael, Guerra, política y moral, trad. de Tomás Fernández Aúz y Beatriz Eguibar, Editorial Paidós, Barcelona, 2001. 
—, Just and Unjust Wars: A Moral Argument with Historical Illustrations, Basic Books, New York, 2006.

Zolo, Danilo, La justicia de los vencedores: de Nuremberg a Bagdad, trad. de Elena Bossi, Editorial Trotta, Madrid, 2006. 